\title{
B-FACTORY INTERMEDIATE DC MAGNET POWER SYSTEMS RELIABILITY MODELING AND RESULTS*
}

\author{
P. Bellomo, A. Donaldson, D. MacNair, SLAC, Stanford, CA 94309, USA
}

\section{Abstract}

The B-Factory is a high-energy physics facility for studying matter versus anti-matter asymmetry. It utilizes 200 Intermediate DC power systems, employing 2.5 to $17 \mathrm{~kW}$ switchmode converters, to supply beam-shaping magnets with regulated current. Redundancy and modularity were considered to maximize reliability and minimize mean time to replace (MTTR), within technical limitations and cost constraints. Described are the configurations that were considered and reliability prediction models. The SLAC decision to employ a single converter was sound. However, 2 years of operation have confirmed that converter reliability must be improved.

\section{INTRODUCTION}

The B-Factory was authorized on the premise that the B-Mesons would be generated at factory production levels. Like a commercial factory, the facility must achieve high availability in order to obtain meaningful experimental data to justify its cost and continued operation. The facility utilizes 200 Intermediate DC Power Systems. In view of the large number of systems, it was important to address the issue of availability from the onset of the design and engineering processes.

\section{REQUIRED AVAILABILITY}

The target availability for the B-Factory is $\geq 76 \%$ [1] over a 9-month "mission" interval. This is further broken down into availability allotments for various facility subsystems. The allotment for all the DC Magnet Power Systems is $97 \%$ [1]. The 200 intermediate power systems are a subset of the DC Magnet Power Systems and must achieve $\geq 98 \%$ if the overall facility availability target is to be met.

\section{POWER SYSTEM DESCRIPTION}

A magnet power system typically consists of the subsystems and components shown in Figure 1. The dashed line components have their own availability budgets and are not discussed here.

The converter controller is an integral part of the current stabilization loop. It also communicates the magnet current and converter status to the B-factory operators via global control.

Off-line, switchmode, pulse-width-modulated, $2.5 \mathrm{~kW}$ to $17 \mathrm{~kW}$ converters furnish precise, controlled, and almost pure DC current to the magnets.

A high precision zero-flux transductor forms an integral and important part of an external current stabilization loop. Verification is provided by a monitor transductor.

* Work supported by the U.S. Department of Energy under contract DE-AC03-76SF00515.

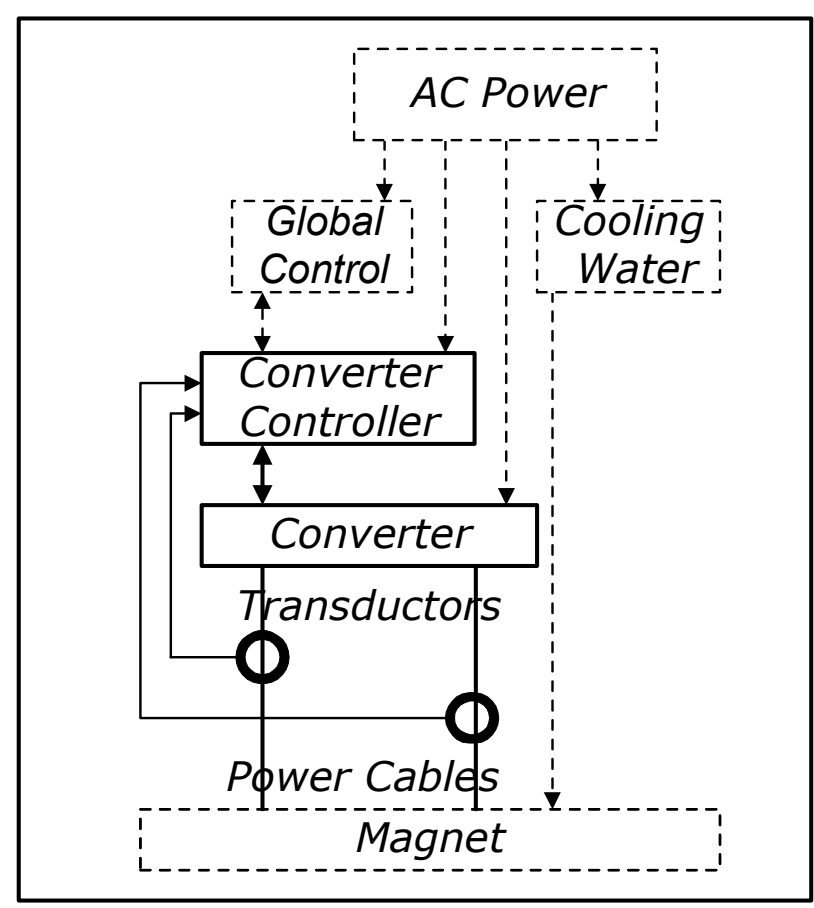

Figure 1: Power System Block Diagram

DC power cables range in size from $2 / \mathrm{C} \# 6 \mathrm{AWG}$ to $500 \mathrm{kcmil}$. They are stranded copper, NEC type TC rated. The cable connectors vary, ranging from miniature, multipin electronic connectors to large power lugs.

\section{RELIABILITY MODELING}

The reliability block diagram shown in Figure 2 represents the power system. Since all components are crucial, the reliability block diagram consists of seriesconnected components.

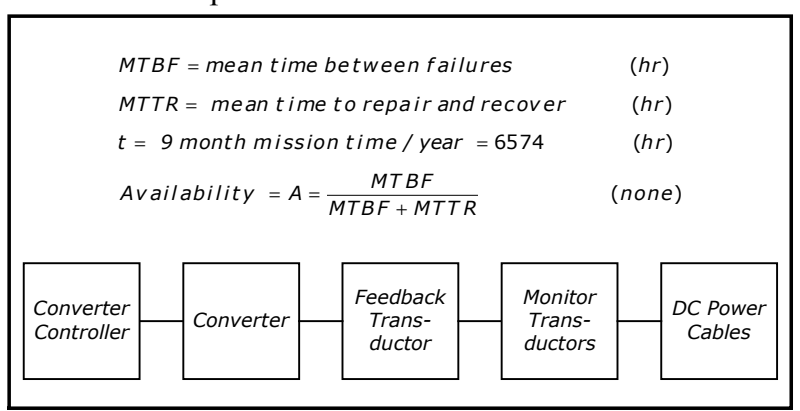

Figure 2: Definitions And Reliability Block Diagram

Failure analysis using MIL-HDBK-217, Parts Stress Method at 30C, with ground benign conditions yielded the component MTBF values shown in Table 1. 


\section{OPERATING RESULTS}

The first group of 70 Intermediate DC Power Systems (with converters provided by Manufacturer A) began operating during December 1997. The remaining 130 power systems (with converters provided by Manufacturer B) began operation a year later. All 200 systems have since been in continuous operation, except when the facility has been shutdown for planned installation of additional systems and physics diagnostics. A total of about 2.6 million operating hours have been logged. The actual availability of components and the 200 power systems is tabulated in Table 2 .

\begin{tabular}{|c|c|c|c|c|}
\hline Component & $\begin{array}{c}\text { MTTR } \\
\text { Hrs }\end{array}$ & Failures & $\begin{array}{c}\text { MTBF } \\
\text { Hrs }\end{array}$ & Availability \\
\hline & & & \multicolumn{2}{|c|}{1 System } \\
\hline Controller & 2 & 9 & 288,889 & 0.9999931 \\
\hline Converter & 2 & 102 & 25,490 & 0.9999215 \\
\hline Transductor 1 & 4 & 2 & $1,300,000$ & 0.9999969 \\
\hline Transductor 2 & 4 & 2 & $1,300,000$ & 0.9999969 \\
\hline Cables & 12 & 1 & $2,600,000$ & 0.9999954 \\
\hline \multirow[t]{2}{*}{ System } & & 116 & 22,414 & 0.9999039 \\
\hline & & & \multicolumn{2}{|c|}{200 Systems } \\
\hline Controller & & & 1,444 & 0.9986173 \\
\hline Converter & & & 127 & 0.9845501 \\
\hline Transductor 1 & & & 6,500 & 0.9993850 \\
\hline Transductor 2 & & & 6,500 & 0.9993850 \\
\hline Cables & & & 13,000 & 0.9990778 \\
\hline System & & & 112 & 0.9811321 \\
\hline
\end{tabular}

Table 2: Two-Year Operating Results

\section{FAILURE DETAILS}

\section{Controller Failures}

Three of the 9 controller failures are attributable to the failure of a small off-line DC power supply in the controller. The controllers performed better than anticipated.

\section{Converter Failures}

Table 2 shows that the 200 power systems achieved 0.981 availability and met the 0.98 goal. The converters could have performed better. Their problems are summarized below.

\section{Manufacturer A - 64 Failures}

- 1 input AC circuit breaker mechanical failure. No action needed or taken. This is a random failure.

- 6 rectifier bridge failures, causes still under investigation.

- 18 failures due to an incorrect part in a comparator circuit or an incorrect calibration of the current overload circuit caused spurious "loss of auxiliary power" faults. Both problems have been corrected.

- 39 nuisance trips, for which no cause yet found.

\section{Manufacturer B - 38 Failures}

- 1 input AC circuit breaker mechanical failure.

- $7 \mathrm{AC}$ input connectors that overheated due to loose terminal screws. The manufacturer now tightens screws to a torque specification and has entered connector work onto a QA assembly traveler.

- 5 diode rectifier bridges that failed because of AC over-voltage transients during converter turn-on and turn-off. Phase to neutral snubber circuits corrected the problem.

- 3 low line detectors that required calibration and were corrected.

- 22 problems with circuit board voltage breakdowns. The problem stems from uncontrolled environment dust that accumulates during the day and then turns into mud with the evening fog. Conformal coatings are under consideration.

- There were also 7 fan failures, listed here only for reference. These were replaced during machine downtime and no availability loss was incurred.

\section{CONCLUSIONS}

The approach to estimate and confirm system reliability and availability is relatively straightforward.

Converters are the weak link. Redundancy can dramatically improve availability. However, more is involved than just paralleling converters. To be effective the converters must be protected against single-point failures.

Democratic load-current-sharing is preferred over master-slave schemes, particularly if more than 2 converters are parallel connected. Even when 2 converters are connected in parallel the master-slave scheme is not ideal because master loss also disables the slave.

In some situations modularity and hot-swap capability will not significantly reduce MTTR and therefore offer minimum benefit.

Systems with redundant converters cost more, depending upon the converter configuration, which in turn is dictated by how much availability is needed.

For the B-Factory situation, the target availability was attained. SLAC made the right choice by employing just a single converter in each power system. Power system cost and space were minimized

\section{ACKNOWLEDGMENTS}

The authors are indebted to the Power Systems Operations East technicians and supervisors who install, test, maintain and repair the subject power supplies. System reliability, availability and rapid MTTR are a direct result of their skill and dedication.

\section{REFERENCES}

[1] PEP-II (B-Factory) internal Technical Note 100, July 18,1995

[2] Milan Jovanovic, David Crow and Lieu Fang-Yi "A Novel, Low-Cost Implementation of "Democratic" Load-Current Sharing of Paralleled Converter Modules", IEEE Transactions on Power Electronics, Volume 11, Number 4, July 1996.

[3] Paul O'Boyle and Steve Kugler "Redundancy and Hot Swapping Keep Systems Running", Electronic Design, November 1997 